\title{
Response to Hermida
}

\author{
Hypertension Research (2013) 36, 473-475; doi:10.1038/hr.2013.6; published online 21 February 2013
}

We have recently published the largest crosssectional study to date that provides a direct comparison of ambulatory blood pressure (ABP) with home blood pressure (BP) measurements in terms of their ability to detect white coat and masked hypertension phenomena among 613 untreated or treated subjects attending a hypertension clinic. ${ }^{1}$

Hermida et $a .^{2}{ }^{2}$ criticized our paper for ignoring night time ABP measurements, and using only day time (awake) ABP for defining white coat and the masked hypertension phenomena. ${ }^{1}$ This criticism is valid given the accumulating evidence on the prognostic ability of night time $A B P$, which in some studies has exceeded that of day time measurements. ${ }^{3}$ In addition, it appears reasonable that, as far as possible, all of the information provided by $24-\mathrm{h}-\mathrm{ABP}$ monitoring should be used in diagnosing hypertension phenotypes.

\section{Definitions of white coat and masked hypertension phenomena}

We looked at the definitions applied for white coat and masked hypertension phenomena in published papers. White coat and the masked hypertension phenomena have been extensively investigated in crosssectional diagnostic trials. In line with our study, ${ }^{1}$ the cross-sectional studies that evaluated white coat and masked hypertension phenomena have been based almost exclusively on day time or awake $\mathrm{ABP}$ measurements. $^{4,5}$ This was also the case in long-term outcome trials that assessed the prognostic significance of these phenomena, which also used day time or awake ABP measurements, ${ }^{6-10}$ with a few exceptions that used average 24 -h-ABP values. ${ }^{11,12}$

Several guideline documents and statements by hypertension societies have provided recommendations on the evaluation of white coat and the masked hypertension phenomena in clinical practice. The 2007 European Society of Hypertension guidelines defined white coat hypertension on the basis of day time or $24-\mathrm{h}-\mathrm{ABP} .^{13}$ On the other hand, the American Heart Association recommended the use of awake $\mathrm{ABP}$ for the diagnosis of white coat hypertension. ${ }^{14,15}$ More recently, the UK National Institute for Health and Clinical Excellence, in its recommendations for the management of hypertension, defined white coat and masked hypertension on the basis of day time ABP. ${ }^{16}$

The above mentioned data on the definitions used for white coat and masked hypertension in short-term and long-term trials, and in hypertension guidelines suggest that nocturnal ABP levels are largely ignored. By defining white coat hypertension on the basis of day time ABP measurements, there might be cases with low day time ABP but elevated night time ABP that remain undetected. On the other hand, by defining masked hypertension on the basis of day time measurements, there might be cases with low day time ABP but elevated night time $\mathrm{ABP}$ that also remain undetected.

Isolated nocturnal hypertension: additional data analysis

We investigated this issue raised by Hermida et $a .^{2}$ by performing additional analysis of our data, with the aim of evaluating (i) the proportion of subjects who had elevated nocturnal ABP, but have been labeled as white coat hypertensive on the basis of low day time ABP and, (ii) the proportion of subjects with masked hypertension due to isolated nocturnal ABP elevation, who have been missed (classified as normotensives) because of low day time ABP.

According to our initial analysis, the white coat hypertension phenomenon was present in 88 of the 613 study subjects $(14.4 \%)$ when night time (awake) ABP was ignored. ${ }^{1}$ When night time (asleep) ABP was also evaluated, one quarter of these subjects $(n=23,3.8 \%)$ were not classified as white coat hypertensives because of elevated night time ABP (Table 1). As expected, these subjects tended to have higher 24-h-ABP levels than those with low day time and night time ABP or normotensives (low clinic, day time and night time ABP, Table 2). It is important to note, however, that only 5 out of these 23 subjects had an elevated 24-h-ABP (systolic and/or diastolic > 130/80 $\mathrm{mm} \mathrm{Hg}$ ). Moreover, when a $5 \mathrm{~mm} \mathrm{Hg}$ gray zone of diagnostic uncertainty was applied to define isolated nocturnal hypertension $(>5 \mathrm{~mm} \mathrm{Hg}$ above the diagnostic threshold for night time $\mathrm{ABP})$, only 10 subjects $(1.6 \%)$ changed classification as a result of nocturnal hypertension (Table 1).

We also looked at the classification of the masked hypertension phenomenon, which was observed in 94 study subjects (15.3\%) in our initial analysis that ignored night time $\mathrm{ABP}^{1}{ }^{1}$ When night time ABP was taken into account, there were 27 more cases of masked hypertension due to isolated nocturnal hypertension (Table 3). Subjects with isolated nocturnal hypertension tended to have lower 24-h-ABP levels than those with masked hypertension due to day time ABP elevation only, or day and night time $\mathrm{ABP}$ elevation (Table 4). It is important to note that average 24- $\mathrm{h}$ ABP was normal in 24 of the 27 subjects with isolated nocturnal masked hypertension. Moreover, when a $5 \mathrm{~mm} \mathrm{Hg}$ gray zone of diagnostic uncertainty was applied to define isolated nocturnal hypertension ( $>5 \mathrm{~mm} \mathrm{Hg}$ above the diagnostic threshold for night time ABP), only seven subjects (1.1\%) changed classification because of isolated nocturnal hypertension (Table 3).

The above analyses suggest that in our study sample, by taking into account night time $A B P$ in the detection of white coat and masked hypertension phenomena, there are few cases which the diagnosis changes as a result of isolated nocturnal hypertension. More importantly, in most of 
Table 1 Prevalence of the white coat hypertension phenomenon defined on the basis of clinic blood pressure and several different aspects of the ambulatory blood pressure profile among 613 subjects attending a hypertension clinic

\begin{tabular}{|c|c|c|c|c|}
\hline & \multicolumn{3}{|c|}{$\begin{array}{l}\text { Different definitions of white } \\
\text { coat hypertension }\end{array}$} & \multirow{3}{*}{$\begin{array}{c}\begin{array}{c}\text { White coat } \\
\text { hypertensives }\end{array} \\
\text { (\%) }\end{array}$} \\
\hline & Clinic & Awake & & \\
\hline & $B P$ & $A B P$ & Asleep $A B P$ & \\
\hline Day time $\mathrm{WCH}$ & High & Low & Ignored & $88(14.4)$ \\
\hline Day and night time $\mathrm{WCH}$ & High & Low & Low & $65(10.6)$ \\
\hline WCH with elevated night time ABP only & High & Low & High & $23(3.8)$ \\
\hline $\begin{array}{l}\text { Day time } \mathrm{WCH} \text { with high Night time ABP that is } \\
\text { clinically relevant }\end{array}$ & High & Low & $\begin{array}{l}\text { High ( }>5 \mathrm{~mm} \mathrm{Hg} \text { above } \\
\text { night time ABP threshold) }\end{array}$ & $10(1.6)$ \\
\hline
\end{tabular}

Abbreviations: $\mathrm{ABP}$, ambulatory blood pressure; $\mathrm{BP}$, blood pressure; $\mathrm{WCH}$, white coat hypertension.

Table 2 Characteristics of subjects with white coat hypertension phenomenon defined on the basis of clinic blood pressure and several different aspects of the ambulatory blood pressure profile among 613 subjects attending a hypertension clinic

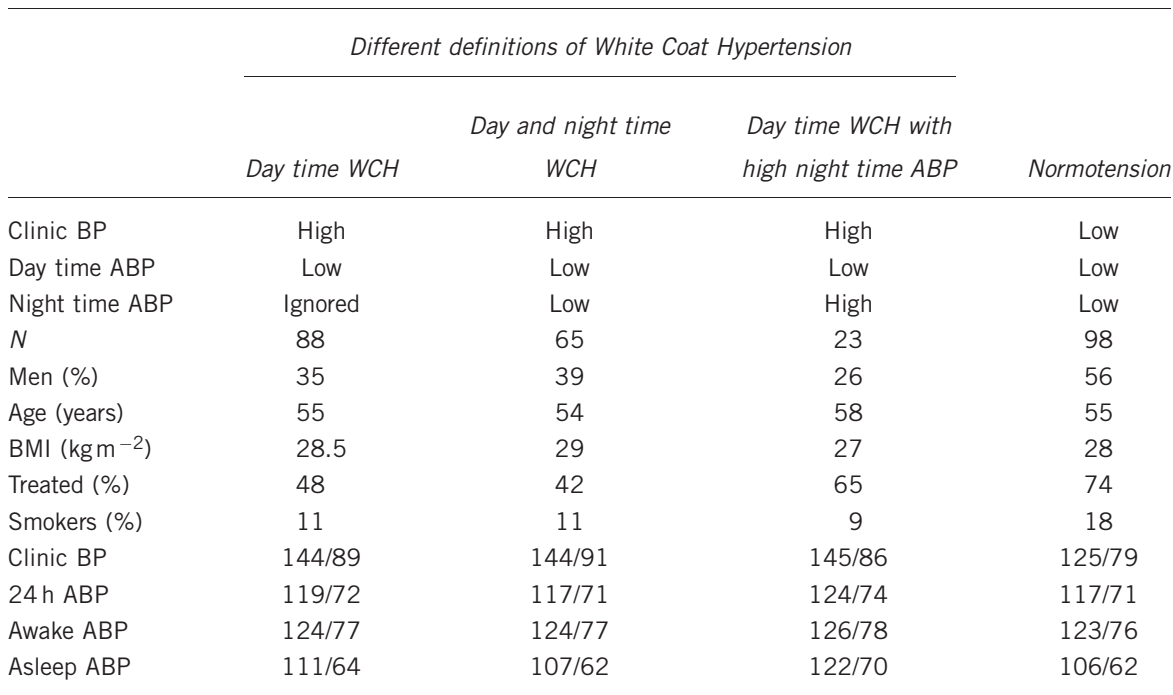

Abbreviations: $\mathrm{ABP}$, ambulatory blood pressure systolic/diastolic in $\mathrm{mm} \mathrm{Hg}$; $\mathrm{BMI}$, body mass index; $\mathrm{BP}$, blood pressure systolic/ diastolic in $\mathrm{mm} \mathrm{Hg}$; $\mathrm{WCH}$, white coat hypertension.

Table 3 Prevalence of the masked hypertension phenomenon defined on the basis of clinic blood pressure and several different aspects of the ambulatory blood pressure profile among 613 subjects attending a hypertension clinic

Masked

Different definitions of masked hypertension

hypertensives

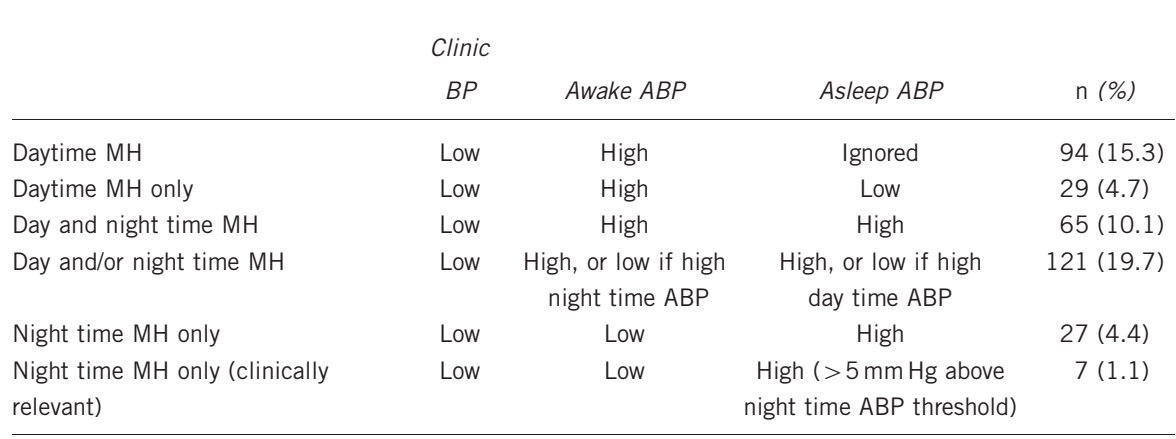

Abbreviations: $\mathrm{ABP}$, ambulatory blood pressure; $\mathrm{BP}$, blood pressure; $\mathrm{MH}$, masked hypertension. these cases, individuals have a normal average 24-h-ABP, which makes the diagnosis of ABP hypertension and the need for treatment questionable.

\section{Remaining research questions}

In our cross-sectional study, the vast majority of the participants attending a hypertension clinic had uncomplicated hypertension and low to moderate cardiovascular risk. ${ }^{1}$ There are three important issues that cannot be investigated in our data set. The first is the prevalence of isolated nocturnal hypertension in other populations, such as patients with established cardiovascular disease, nephropathy, diabetes or sleep apnea, in whom the prevalence of nondipping is higher than in those with uncomplicated hypertension. Second, we could not investigate whether individuals with isolated nocturnal hypertension have a higher cardiovascular risk than normotensives. Third, we also could not investigate whether in these cases the selective reduction of night time $\mathrm{BP}$ with drug dosing before bedtime is more effective in preventing cardiovascular events than the usual morning dosing.

The International Database on Ambulatory Blood Pressure In Relation to Cardiovascular Outcomes Investigators included 8711 individuals from 10 populations, and identified 577 untreated individuals (6.4\%) with isolated nocturnal hypertension (low office and day time ABP). After a follow-up of 10.7 years, this condition was found to be associated with a higher overall mortality (hazard ratio $1.29, P=0.045$ ) and cardiovascular event risk $(1.38, P=0.037) .{ }^{17}$ Several studies in diabetic ${ }^{18,19}$ and non-diabetic subjects $^{20,21}$ have suggested that elevated nocturnal ABP should be taken into account in decision making, even when day time ABP levels are low.

The usefulness of bedtime dosing of antihypertensive drug treatment aimed at improving nocturnal BP control, and thereby providing more effective protection against cardiovascular events has been inadequately investigated. $^{22} \mathrm{~A}$ recent study in hypertensive patients with nephropathy who were followed for 5.4 years showed that taking at least one antihypertensive drug at bedtime improved the control of nocturnal and 24-h-ABP and reduced the risk of cardiovascular events compared to taking all drugs in the morning. ${ }^{23}$ On the other hand, another report by the African American Study of Kidney Disease showed that bedtime dosing of once-daily antihypertensive treatment or the addition 
Table 4 Characteristics of subjects with masked hypertension phenomenon defined on the basis of clinic blood pressure and several different aspects of the ambulatory blood pressure profile among 613 subjects attending a hypertension clinic

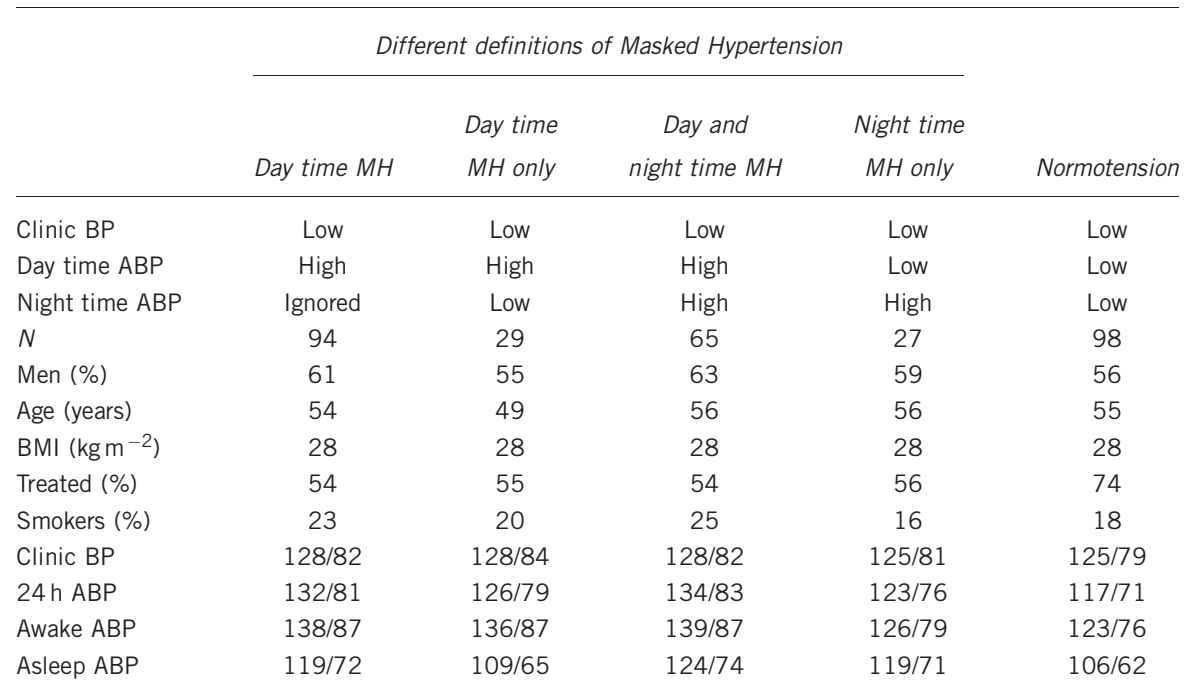

Abbreviations: $\mathrm{ABP}$, ambulatory blood pressure systolic/diastolic in $\mathrm{mm} \mathrm{Hg}$; BMI, body mass index; $\mathrm{BP}$, blood pressure systolic/ diastolic in $\mathrm{mm} \mathrm{Hg}$; $\mathrm{MH}$, masked hypertension.

of drugs taken at bedtime did not significantly reduce nocturnal BP compared to morning dosing. ${ }^{24}$

Despite the considerable number of studies that have demonstrated the prognostic relevance of nocturnal hypertension, there is still no conclusive evidence on whether a treatment strategy specifically targeting nocturnal $\mathrm{BP}$ can eliminate the associated cardiovascular risk. ${ }^{7,22}$ Although it seems reasonable that all aspects of the 24-h-BP profile should be normalized, randomized trials are still needed to demonstrate whether more complex and individualized treatment regimens can achieve more efficient cardiovascular protection than morning dosing with longacting drugs.

\section{CONFLICT OF INTEREST}

The authors declare no conflict of interest.

Efthimia G Nasothimiou, Maria Dafni, Leonidas G Roussias and George S Stergiou

Hypertension Center, Third University Department of Medicine, Sotiria Hospital, Athens, Greece E-mail: gstergi@med.uoa.gr

1 Nasothimiou EG, Tzamouranis D, Rarra V, Roussias LG, Stergiou GS. Diagnostic accuracy of home vs, ambulatory blood pressure monitoring in untreated and treated hypertension. Hypertens Res 2012; 35: 750-755.

2 Hermida RC, Ayala DE, Smolensky MH, Mojón A, Fernández JR, Portaluppi F. Asleep blood pressure: relevance to the proper definition of isolated-office and masked hypertension. Hypertens Res 2013; 36: 471-472.

3 Hansen TW, Li Y, Boggia J, Thijs L, Richart T, Staessen JA. Predictive role of the nighttime blood pressure. Hypertension 2011; 57: 3-10.

4 Stergiou GS, Bliziotis IA. Home blood pressure monitoring in the diagnosis and treatment of hypertension: a systematic review. Am J Hypertens 2011; 24: 123-134.

5 Hodgkinson J, Mant J, Martin U, Guo B, Hobbs FD, Deeks JJ, Heneghan C, Roberts N, McManus RJ. Relative effectiveness of clinic and home blood pressure monitoring compared with ambulatory blood pressure monitoring in diagnosis of hypertension: systematic review. BMJ 2011; 342: d3621.

6 Fagard RH, Cornelissen VA. Incidence of cardiovascular events in white-coat, masked and sustained hypertension versus true normotension: a meta-analysis. J Hypertens 2007; 25: 2193-2198.

7 Hansen TW, Kikuya M, Thijs L, Björklund-Bodegård K, Kuznetsova T, Ohkubo T, Richart T, Torp-Pedersen C, Lind L, Jeppesen J, Ibsen H, Imai Y, Staessen JAIDACO Investigators. Prognostic superiority of daytime ambulatory over conventional blood pressure in four populations: a meta-analysis of 7,030 individuals. J Hypertens 2007; 25: 1554-1564.

8 Angeli F, Reboldi G, Verdecchia P. Masked hypertension: evaluation, prognosis, and treatment. $A m \mathrm{~J}$ Hypertens 2010; 23: 941-948.

9 Pierdomenico SD, Cuccurullo F. Prognostic value of white-coat and masked hypertension diagnosed by ambulatory monitoring in initially untreated subjects: an updated meta analysis. Am J Hypertens 2011; 24: 52-58.

10 Bangash F, Agarwal R. Masked hypertension and whitecoat hypertension in chronic kidney disease: a metaanalysis. Clin J Am Soc Nephrol 2009; 4: 656-664.

11 Kario K, Shimada K, Schwartz JE, Matsuo T, Hoshide S, Pickering TG. Silent and clinically overt stroke in older Japanese subjects with white-coat and sustained hypertension. J Am Coll Cardiol 2001; 38 238-245.

12 Mancia G, Facchetti R, Bombelli M, Grassi G, Sega R. Long-term risk of mortality associated with selective and combined elevation in office, home, and ambulatory blood pressure. Hypertension 2006; 47: 846-853.

13 Mancia G, De Backer G, Dominiczak A, Cifkova R, Fagard R, Germano G, Grassi G, Heagerty AM, Kjeldsen SE, Laurent S, Narkiewicz K, Ruilope L, Rynkiewicz A, Schmieder RE, Boudier HA, Zanchetti
A, Vahanian A, Camm J, De Caterina R, Dean V, Dickstein K, Filippatos G, Funck-Brentano C, Hellemans I, Kristensen SD, McGregor K, Sechtem U, Silber S, Tendera M, Widimsky $P$, Zamorano JL, Erdine S, Kiowski W, Agabiti-Rosei E, Ambrosioni $\mathrm{E}$, Lindholm LH, Viigimaa M, Adamopoulos S, Agabiti-Rosei E, Ambrosioni E, Bertomeu V, Clement D, Erdine S, Farsang C, Gaita D, Lip G, Mallion JM, Manolis AJ, Nilsson PM, O'Brien E, Ponikowski P, Redon J, Ruschitzka F, Tamargo J, van Zwieten P, Waeber B, Williams B. Management of Arterial Hypertension of the European Society of Hypertension; European Society of Cardiology. J Hypertens 2007; 25: 1105-1187.

14 Pickering TG, Hall JE, Appel LJ, Falkner BE, Graves J, Hill MN, Jones DW, Kurtz T, Sheps SG, Roccella EJ. Subcommittee of Professional and Public Education of the American Heart Association Council on High Blood Pressure Research. Recommendations for blood pressure measurement in humans and experimental animals: part 1: blood pressure measurement in humans: a statement for professionals from the Subcommittee of Professional and Public Education of the American Heart Association Council on High Blood Pressure Research. Hypertension 2005; 45: 142-161.

15 Verdecchia $P$, O'Brien $E$, Pickering $T$, Staessen JA Parati G, Myers M, Palatini P. European Society of Hypertension Working Group on Blood Pressure Monitoring. When can the practicing physician suspect white coat hypertension? Statement from the Working Group on Blood Pressure Monitoring of the European Society of Hypertension. Am J Hypertens 2003; 16: 87-91.

16 National Institute for Health and Clinical Excellence. Clinical management of primary hypertension in adults 2011. www.nice.org.uk/nicemedia/live/13561/56008/ 56008.pdf. Assessed 29 November 2012.

17 Fan HQ, Li Y, Thijs L, Hansen TW, Boggia J, Kikuya M, Björklund-Bodegård K, Richart T, Ohkubo T, Jeppesen J, Torp-Pedersen C, Dolan E, Kuznetsova T, StolarzSkrzypek K, Tikhonoff V, Malyutina S, Casiglia E, Nikitin Y, Lind L, Sandoya E, Kawecka-Jaszcz K, Imai Y, Ibsen H, O'Brien E, Wang J, Staessen JA. International Database on Ambulatory Blood Pressure In Relation to Cardiovascular Outcomes Investigators. Prognostic value of isolated nocturnal hypertension on ambulatory measurement in 8711 individuals from 10 populations. J Hypertens 2010; 28: 2036-2045.

18 Wijkman M, Länne T, Engvall J, Lindström T, Ostgren CJ, Nystrom FH. Masked nocturnal hypertension-a novel marker of risk in type 2 diabetes. Diabetologia 2009; 52: 1258-1264.

19 Rodrigues TC, Canani LH, Viatroski RS, Hoffmann LH, Esteves JF, Gross JL. Masked hypertension, nocturnal blood pressure and retinopathy in normotensive patients with type 1 diabetes. Diabetes Res Clin Pract 2010; 87: 240-245.

20 Hoshide S, Ishikawa J, Eguchi K, Ojima T, Shimada K, Kario K. Masked nocturnal hypertension and target organ damage in hypertensives with well-controlled self-measured home blood pressure. Hypertens Res 2007; 30: 143-149.

21 Hermida RC, Ayala DE, Mojón A, Fernández JR. Sleeptime blood pressure and the prognostic value of isolated-office and masked hypertension. $A m \mathrm{~J}$ Hypertens 2012; 25: 297-305.

22 Stergiou GS, Nasothimiou EG. Does dosing antihypertensive drugs at night alter renal or cardiovascular outcome: do we have the evidence? Curr Opin Nephrol Hypertens 2008; 17: 464-469.

23 Hermida RC, Ayala DE, Mojón A, Fernández JR. Bedtime dosing of antihypertensive medications reduces cardiovascular risk in CKD. J Am Soc Nephrol 2011; 22: 2313-2321.

24 Rahman M, Greene T, Phillips RA, Agodoa LY, Bakris GL, Charleston J, Contreras G, Gabbai F, Hiremath L, Jamerson K, Kendrick C, Kusek JW, Lash JP, Lea J, Miller 3rd ER, Rostand S, Toto R, Wang X, Wright Jr JT, Appel LJ. A trial of 2 strategies to reduce nocturnal blood pressure in blacks with chronic kidney disease. Hypertension 2013; 61: 82-88. 